\title{
Objective and Subjective Determinants for Regional Economy's Digitalization
}

Submitted 10/05/20, 1 st revision 16/06/20, 2nd revision 11/07/20, accepted 30/07/20

\begin{abstract}
Galazova S.S. ${ }^{1}$, Bekbergeneva D.E. ${ }^{2}$
Abstract:

Purpose: The article is aimed at studying the objective and subjective conditions of digitalization of the regional economy, which could be encouraging or restrictive.

Design/Methodology/Approach: Digitalization of the key and auxiliary business processes of regional economy's entites requires a justification of promising areas of partial or compltete restructuring of the economic policy of enterprises, the transfer of all or individual operations to the digital space. For the effective implementation of this task, it is necessary to take into account the maximum number of positive and negative factors affecting the success of the implementation of digital tools. Description and breakdown of such factors is presented in this article. The methodological background of the research is based on a systematic approach and factor analysis in order to study external and internal opportunities and limitations of the digital economy's development in the regions.
\end{abstract}

Findings: The study revealed specific subjective and objective restraints and threats preventing enterprises to actively implement technological solutions for processing large amounts of data and digitalization of business processes. The obstructive restraints and constructive opportunities that subjectively affect the development of digital tools are identified and substantiated. The author described the objective drivers of growth and threats to the growth of the digital economy. People and infrastructure a defined as the points of growth, becoming mandatory areas of investment in the digitalization of business processes of enterprises and social processes of non-profit organizations and public authorities.

Practical implications: In practice, the results of the study will help determining vectors for the implementation of digitalization tools in the regions, taking into account the conditions for their implementation and supporting the identified growth points.

Originality/value: The study has original results clarifying the conditions for the digitalization of the regional economy and determining the specific applications of the efforts of the subjects of economic relations.

Keywords: Digital economy, regional economy, constructive opportunities, obstructive restraints, growth drivers, growth threats, growth points.

JEL Classification Codes: F02, F15, F63.

${ }^{l}$ D.Sc in Economics, Professor, Khetagurov North Ossetian State University, Vladikavkaz, Russian Federation

${ }^{2}$ Ph.D in Economics, Associate Professor, Orenburg branch of RANEPA, Orenburg, Russian Federation, dinabekber@mail.ru 


\section{Introduction}

The digitalization of the regional economy involves a paradigm shift in the economic development of various industries and activity areas in the region. The key criterion for the efficiency of business processes of economic entities is the achievement of sustainable development due to a constant and smooth increase in performance indicators, timely adaptation of activity strategies to changes in the internal and external environment, meeting and anticipating the needs of consumers of products and services.

The introduction of digital economy tools into the activities of enterprises is uneven in different regions and industries. Digitalization is actively perceived by organizations in the financial sector, banks, insurance companies, educational organizations, media and entertainment. Difficulties in the proper perception of modern digital techniques arise in the industries that are traditionally basic for the Russian economy like mining and processing industries, agriculture, construction.

\section{Materials and methods}

Various aspects of digital economy instruments' implementation were considered in the following studies: OECD, 2020; Zyablitskaya and Sultygov 2018; Dubov, 2018; Kapranova, 2018; Geissbauer, Vedso and Schrauf, 2016. There are also scientific studies devoted to the features of digitalization in different sectors of the Russian economy (Akberdina, 2018; Ognivtsev, 2019; Khripunova, Litvin and Golovinskaya, 2019).

Nevertheless, despite the studies of the possibilities and prospects for the development of the digital economy, the study of drivers, barriers and growth points in the digitalization of the regional economy has been insufficiently conducted and these issues require further research.

The study utilized a systematic approach and factor analysis.

\section{Results}

Digitalization of the regional economy is a comprehensive, multi-vector phenomenon that contains different directions and could be implemented in different sectors of the economy.

The hypothesis of the study suggests that the difficulties in implementing the tools of digital economy are associated both with the subjective unwillingness of enterprise managers to change their activities, and with objective reasons that complicate the full transition of all business processes of the enterprise to the digital space. 
The authors define the subjective conditions of digitalization as follows: positive - as constructive opportunities, and negative - as obstructive restraints. We present the objective aspects of external influence on the peculiarities of the development of the digital economy in the region as growth drivers and growth threats.

The constructive possibilities for the implementation of digital economy tools include the following:

- benefits gained by economic entities from the introduction of modern information and communication technologies like reduction of transaction costs, release of labor resources, accurate modeling of consumer behavior and forecasting the state of market conditions;

- fast adoption of optimal management decisions based on timely processing of relevant and detailed information, prompt implementation of initiatives and flexible monitoring and control over the implementation of plans and programs;

- active support by public authorities through special programs and financial solutions for enterprises engaged in the digitalization of their business processes.

The obstructive constraints are:

- conservative mentality of the top and middle management of large commercial enterprises, which does not allow managers to fully accept and effectively use digital tools;

- insufficient funds and lack of understanding of the importance of introducing information software products for the analysis of big data and interaction with consumers in small businesses;

- the lack of IT specialists at the enterprises with the required level of professional competence or the reluctance of the management of the enterprise to pay for outsourcing informatization services, which leads to a decrease in the quality of implementation of the information and communication system at the enterprise;

- low digital literacy of consumers of products and services. That's why enterprises are afraid of transfering all their business processes into the digital space, since this fact may be perceived by consumers with distrust, or even with rejection.

The objective drivers of digital economy growth are:

- production automation and the development of the Internet of Things (IoT). These technologies are being actively implemented not only in the consumer (household appliances, cars, cell phones included in a single information space), but also in the industrial sector of the economy (automation of production lines, tire and construction equipment sensors, the use of drones in agriculture), which can significantly increase the income of enterprises and reduce the cost of repair and maintenance of equipment;

- digital design (Naumkin, 2018), which implies the creation of digital twins of economic or social processes to encourage the phenomena occurring in them and predict future changes with minimal costs; 
- development of the mobile Internet and the creation of cross-cultural communications through various digital media (computers, tablets, mobile phones), which pushes enterprises to use special programs and databases to form interaction with consumers, their own employees, stakeholders;

- clustering of economic systems, contributing to the development of related industries on the basis of a common information and communication space, which implies active interaction of government bodies and regional business communities to form an optimal balance of interests of cluster members.

Objective threats to the growth of the digital economy include:

- cybersecurity problems, which involves the introduction of encryption and crypto protection systems, which are especially relevant and used in the banking sector, the defense industry and government bodies, while in the light and food industries, trade, services, tourism, cybersecurity systems are rarely implemented due to their high cost development and maintenance of this system, especially in small business;

- the lack of specialized digital platforms providing taking into account the specifics of a particular business and the lack of free information and communication resources of small enterprises for the development of these electronic platforms, while small businesses in the region need comfortable conditions for conducting transactions and a variety of methods and forms of payment and delivery of various goods and the provision of services;

- the instability of the financial sector, the growth of inflation, which complicates the processes of investing enterprises in digital technologies and requires government bodies to pursue a policy of stimulating the digitalization of business processes by commercial enterprises and non-profit organizations;

- the impossibility of implementing complex IT solutions in some territories of the country due to the specifics of the local economy or unfavorable geographic or climatic conditions.

\section{Discussion}

The growth drivers of the digital economy "are seen as driving forces of economic growth leading to significant economic shifts and have an impact on entire areas of business, the labor market and the way people live" (Bahl, 2016). Potential gains from the digital economy could help to solve the problems associated with economic inequality of countries or regions (Beerepoot and Lambregts, 2015). Digital platforms could help overcoming the challenges posed by ineffective and corrupt market and labor institutions in developing countries and underperforming regions (Lendonvirta, 2016). We believe that digital platforms are not a driver (that is, a catalyst for change), but the main instrument for transforming the digital economy.

Scientists consider, for example, the slowdown in the use of new digital technologies or even opposition to their implementation in the economic activities of enterprises as threats to the development of the digital economy due to the low level of digital skills and pervasion of technologies within the regional economy. The authors also 
aware of the possible marginalization of workers who performed routine operations and were replaced by automata, robots, and artificial intelligence, and their unwillingness to retrain and adopt new digital skills (Martin, 2016).

We have identified two main points of growth of the digital economy: people and infrastructure. Considering the role of people in the digitalization of the regional economy, it is necessary to highlight specialists who ensure the development of the digital environment, and users of digital resources who are looking for information, analyzing data, developing and implementing management decisions. Therefore, investments should be aimed at developing the professional competencies of IT specialists and increasing the digital literacy of employees and the general population.

The second priority is the development of technological and communication infrastructure to provide business processes of the enterprise with technologies, software and hardware solutions for collecting, digitizing, storing, transferring and using protected information.

\section{Conclusion}

Thus, the digitalization of the regional economy is encouraged by growth drivers and constructive opportunities, but objective threats and obstructive barriers are limited, and it must be borne in mind that the active development of the digital economy is being held back not only for subjective, but also for objective reasons. Particular importance in the development of the digital economy should be given to the following growth points: the development of digital infrastructure and the improvement of the professional competencies of IT specialists and digital literacy of consumers.

\section{References:}

Akberdina, V.V. 2018. Stages of transformation of industry in the context of digitalization of the economy. Actual problems of economics and management: proceedings of the VI All-Russian scientific-practical conference with international participation, 80-83.

Bahl, M. 2016. The Work Ahead: The Future of Businesses and Jobs in Asia Pacific's Digital Economy. Available at: https://www.cognizant.com/whitepapers/the-workahead-the-future-of-business-and-jobs-in-asia-pacifics-digital-economycodex2255.pdf

Beerepoot, N., Lambregts, B. 2015. Competition in Online Job Marketplaces. Global Networks, 2(15), 236-255.

Dubov, B. 2018. Digital economy and drivers of digitalization in Russia. Available online: https://www.crn.ru/news/detail.php?ID=127168

Geissbauer, R., Vedso, J., Schrauf, S. 2016. Industry 4.0: Building the Digital Enterprise. Available at: https://www.pwc.com/gx/en/industries/industries-4.0/landingpage/industry-4.0-building-your-digital-enterprise-april-2016.pdf.

Kapranova, L.Yu. 2018. Digital economy in Russia: state and development prospects. Economics and Management, 2, 58-69. 
Khripunova, M.B., Litvin, P.O., Golovinskaya, I.V. 2019. The era of the digital economy: digital education as an integral part of the digitalization of the economy. Economics and Management: Problems, Solutions, 3(14), 159-164.

Lehdonvirta, V. 2016. Global Online Labour Markets. Presented at 3rd ISA Forum of Sociology, Vienna, 1-14 July, available at: https://isaconf.confex.com/isaconf/forum2016/webprogram/Paper79343.html

Martin, D. 2016. Socio-digital Practices of Collective Action in Online Labour Platforms, Proccedings of te Connected Life conference, Oxford, UK, 20-21 June.

Naumkin, M. 2018. Five trends of the digital economy. Available online: https://rb.ru/opinion/ekonomika-rossii/.

OECD. 2020. The European Digital Strategy. Available at: https://ec.europa.eu/digitalsingle-market/en/content/european-digital-strategy.

Ognivtsev, S.B. 2019. Digitalization of the economy and the economy of digitalization of the agro-industrial complex. International Agricultural Journal, 2 (368), 77-80.

Zyablitskaya, N.V., Sultygov, M.M. 2018. Digitalization of the Economy and its Impact on the Management Processes of Russian Enterprises. Financial Economics, 6, 54-55. 